\title{
Medicine, music and the mind
}

\author{
Jason Warren
}

No one has ever died for lack of music, but nevertheless for many people a life without music would hardly be worth living. Physicians have good reason to care about something so important to the equanimity of so many of their patients but, of course, the relations between music and medicine go far beyond the merely cordial.

The medicinal properties of music were already well-recognised by the Psalmist and by the Asclepiads (Apollo governed both arts), and the cranial trephines and bone flutes left behind by our cavedwelling forebears hint at a shared past that is far more ancient. Beyond that, there is the nagging sense that music captures something quintessential about the human predicament, and what it is to be human. No other animal unequivocally produces music (though the productions of songbirds and the great whales have an interesting counterclaim), whereas all human societies do; indeed, music is probably more universal than medicine. Medicine is itself illuminated by music: with the convalescent song of thanksgiving at the heart of his late A minor quartet, Beethoven expresses far more than can be said about the healing art (and perhaps, about human life in general). Music and medicine are forever colliding in the lives of individual humans: there is the often unique neurology of music performance, and the personal histories of the great composers frequently make fascinating case studies. Music and madness are uneasy but familiar bedfellows, and it is not always easy to spot which came first. It is hardly surprising that music should prove endlessly fascinating to doctors and the lay public alike: a recent survey of 'tone deafness' in the UK attracted over 50,000 respondents to take an online test (Stewart, personal communication). Would another ailment provoke such a response?

And yet, there is remarkably little that can be said about music without qualification. Even to define it is problematic, though (like civilisation) it is easy to recognise. Music is often analogised as a language, yet it is next to impossible for it to say anything specific about the world at large, while a human lifetime might be required to decipher the Schubert String Quintet or the Mozart Clarinet Concerto. As an index of human creativity, music is vulnerable to the vagaries of taste, and mood: the Voyager probes that may one day represent our species carry their share of Bach and Mozart, ${ }^{1}$ and yet it seems a shame not to have found room for the Rosenkavalier Trio, a drizzly Coltrane solo, Yesterday, or Danny Boy (to sample just the music of one brief period in one terrestrial culture). As a fast track to our emotional core, music is neither reliable nor unique among human artefacts: it leaves a good many people stone cold, while the susceptible may be equally transported by a poem or picture. One person's divinity is another's auditory cheesecake. ${ }^{2}$ As a metaphor for the human psyche, music performs erratically: the radiant creations of the newly married Schumann and the autumnal masterpieces of the dying Mozart fit the bill well enough, but who would guess that Falstaff was written by an octogenarian or Götterdämmerung by a sociopath? Above all, what is music for? If it started as a means to attract a mate, they are in for a long wait with Bruckner, and for Schoenberg and Stockhausen they might decide not to stay. If music began as a means to achieve social cohesion, where does that leave Gesualdo or Glenn Gould? If it is essentially imitative, at a stretch we have a Trout and a Raindrop, even an Appalachian Spring, but what in nature anticipates the Bach Chaconne? Somehow the gap seems just too wide to span. Perhaps the only thing that is certain about music (so far) is that a human mind is required to apprehend it.

\section{New series}

The intersection of medicine, music and the mind is our theme in this new series which owes its existence to the late Professor Ian McDonald. In addition to his justly celebrated achievements as one of the foremost clinical neuroscientists of his generation, Ian was a fine amateur pianist and musicophile. He wrote eloquently and cogently about his own musical alexia following a cerebral infarct. ${ }^{3}$ His vision for this series, conveyed with typical warmth and wisdom, was to explore the interface between music and the brain, and between music as an aesthetic pursuit and as a subject of neuroscientific study. The series would capitalise on the recent explosion of interest in both the scientific and clinical communities, driven in turn by the extraordinary technical advances of the new brain imaging sciences. In conversations with Ian, the outline of the series gradually took shape. It must start with neuroanatomy, and the brain basis for the perception of music. The focus should then shift, logically, to the more exclusive vistas of musical
Jason Warren PhD FRACP, Honorary Consultant Neurologist, National Hospital for Neurology and Neurosurgery, Queen Square, London 
talent and congenital deficiency, and the neurological problems unique to performing musicians. The nature of musical genius and musical madness should each be represented. Finally, the theme should be set in its wider context: the role of music in society, and an attempt to tackle the great unsolved problem of why it is so important to our species.

It became clear during its composition that the series would be a septet. The musical septet is a rather rare bird, and one which blends disparate voices: generally congenial, sometimes acerbic, and occasionally profound. We modestly hope that our septet shares some of these characteristics, and that Ian would have approved its final form. We dedicate it affectionately to his memory.

\section{References}

1 Voyager Golden Record, 1977. http://en.wikipedia.org/wiki/Voyager_Golden_Record

2 Pinker S. How the mind works. New York: W.W. Norton, 1997.

3 McDonald I. Musical alexia with recovery: a personal account. Brain 2006;129:2554-61. 